Disponível em:

http://editora.unoesc.edu.br/index.php/race

Race, Joaçaba, v. 14, n. 2, p. 537-568, maio/ago. 2015

\title{
GESTÃO SUSTENTÁVEL NA CADEIA DE SUPRIMENTOS E DESEMPENHO INOVADOR EM PROCESSOS: UM ESTUDO NA INDÚSTRIA DO ALUMÍNIO
}

\section{Sustainable management in supply chain and innovative in performance processes: a study in the aluminum industry}


Resumo

O presente estudo teve como objetivo associar a gestão sustentável da cadeia de suprimentos com o desempenho inovador do processo produtivo na indústria do alumínio. Para atingir esse objetivo, utilizaram-se como base os pressupostos teóricos de Pagell e Wu (2009), Makkonen e Van Der Have (2012) e Gunday et al. (2011). O estudo possui uma abordagem qualitativa e é de natureza exploratória e descritiva. Como estratégia de pesquisa, utilizou-se o estudo de caso, desenvolvido a partir de entrevistas semiestruturadas e pesquisa documental. Entre os principais resultados encontrados no caso, foi possível destacar a disposição proativa em prol de políticas e ações que contribuam para a sustentabilidade da cadeia de suprimentos na qual a empresa é componente. As evidências constatadas indicam que as práticas de gestão que configuram a formação de cadeias de suprimentos sustentável fazem parte do escopo estratégico da empresa analisada. Quanto ao desempenho inovador, os resultados verificados a partir das variáveis como $\mathrm{P} \& \mathrm{D}$, patentes, marcas, certificações, renovação nos métodos e sistemas administrativos, fundamentadas pelo modelo conceitual proposto, revelam que a empresa analisada apresenta um perfil inovador em seus processos. Diante desses resultados, o pressuposto de que a integração da sustentabilidade na gestão da cadeia de suprimentos está associada à inovação em processos na indústria de alumínio pôde ser corroborado pelas evidências encontradas no caso.

Palavras-chave: Gestão sustentável. Cadeia de suprimentos. Inovação. Indústria do alumínio.

\section{Sustainable management in supply chain and innovative in performance processes: a study in the aluminum industry}

\section{Abstract}

This study aimed to associate the sustainable management of the supply chain with the innovative performance of the production process in the aluminum industry. To achieve this goal, we used as a base the theoretical assumptions of Pagell and Wu (2009), Makkonen and Van Der Have (2012) and Gunday et al. (2011). The study has a qualitative and exploratory and descriptive approach. As a research strategy, we used the case study, developed from semi-structured interviews and documentary research. Among the main findings of the case, it was possible to highlight the proactive provision in favor of policies and actions that contribute to the sustainability of the supply chain in which the company is component. The evidences found indicate that management practices that shape the formation of sustainable supply chains are part of the strategic scope of the analyzed company. As for the innovative performance, the results obtained from the variables such as RED, patents, trademarks, certifications, renewal of the methods and administrative systems, founded by the proposed conceptual model, show that the analyzed company features an innovative profile in their processes. From these results, the assumption that the integration of sustainability in the management of the supply chain is associated with innovation in processes in the aluminum industry could be corroborated by the evidence found in the case.

Keywords: Sustainable Management. Supply Chain. Innovation. Aluminum Industry. 


\section{INTRODUÇÃO}

A adoção de uma gestão para a sustentabilidade, que incorpore aspectos econômicos, sociais e ambientais na estratégia e nas operações das organizações, considerando os impactos socioambientais relacionados à atividade produtiva, cada vez mais representa um desafio e está relacionada à obtenção de vantagem competitiva pelas organizações.

A gestão de cadeias de suprimentos e a incorporação da sustentabilidade à sua gestão são iniciativas que estão sendo utilizadas por diferentes organizações, de diferentes segmentos mercadológicos, com o objetivo de obter diferenciais competitivos em relação aos seus concorrentes e conquistar a longevidade em seu mercado.

Nesse cenário, o engajamento das partes interessadas pode se tornar uma das mais importantes ações no entendimento, por parte das organizações, do real significado de desenvolvimento sustentável e sustentabilidade, e de como isso pode agregar valor e responsabilidade a partir das atividades organizacionais.

Considerando a necessidade e a importância de uma gestão focada na sustentabilidade da cadeia produtiva da indústria de alumínio e a importância dessa cadeia no desenvolvimento econômico brasileiro, este estudo teve como objetivo analisar a gestão sustentável da cadeia de suprimentos associada ao desempenho inovador do processo produtivo em uma empresa do setor de alumínio no Brasil.

A existência de poucos estudos teóricos no Brasil que visam aprofundar e relacionar as práticas de gestão sustentável e a inovação na cadeia produtiva do setor de alumínio evidencia a relevância deste estudo. Nesse sentido, os resultados do estudo podem proporcionar um maior conhecimento sobre a gestão sustentável no âmbito da cadeia de suprimentos dessa indústria e as suas relações com o desempenho inovador nos processos das empresas.

\section{CADEIA DE SUPRIMENTOS SUSTENTÁVEL E O DESEMPENHO INOVADOR EM PROCESSOS}

O desenvolvimento sustentável passa a ser uma das principais preocupações no ambiente corporativo dos negócios, principalmente nas cadeias produtivas que causam maior impacto na oferta de condições básicas para a sobrevivência do planeta. O termo sustentabilidade ganha corpo e expressão política na adjetivação da expressão 
desenvolvimento sustentável na década de 1980, fruto da percepção de uma crise ambiental global e de uma conscientização de que os países precisavam descobrir maneiras de promover o crescimento de suas economias sem destruir o meio ambiente ou sacrificar o bem-estar das futuras gerações (NASCIMENTO, 2012).

No âmbito empresarial, a sustentabilidade é operacionalizada, comumentemente, a partir do conceito Triple Bottom Line (TBL), termo apresentado por John Elkington, em 2004, o qual considera não somente as questões econômicas, mas também as questões sociais e do meio ambiente, sugerindo a garantia de oportunidades empresariais e criando um sistema mais transparente, aberto e informativo para os consumidores e demais partes interessadas (SAVITZ; WEBER, 2007).

As três dimensões da sustentabilidade apresentadas pelo $T B L$ devem estar integradas, de modo que, na esfera ambiental, os recursos naturais sejam utilizados de forma a não prejudicar as gerações futuras, reduzindo os impactos da ação dos processos produtivos. Na perspectiva econômica, faz-se necessária a preservação da lucratividade da empresa e o não comprometimento do seu desenvolvimento econômico. $\mathrm{Na}$ esfera social, que inclui a questão da justiça social, o objetivo maior é o desenvolvimento de um mundo mais justo, por meio das relações com todas as partes interessadas na organização (ELKINGTON, 2011).

A inserção da sustentabilidade na concepção e nos modelos de gestão das organizações tem sido objetivo de diversos grupos de interesse, os stakeholders. Esse interesse surgiu para atender a uma demanda imposta pela sociedade, na qual as organizações deveriam ser socialmente responsáveis, propondo planos e ações que compreendessem as dimensões ambiental, social e ética. Essa nova concepção fortaleceu a criação dos mecanismos legais e institucionais de defesa do meio ambiente.

Para Hart e Milstein (2003), a busca pela sustentabilidade deve ser considerada em conjunto, como um portfólio, no qual as estratégias e práticas têm o potencial de reduzir custos e riscos, elevar a reputação e a legitimidade da organização e acelerar o processo de inovação e o reposicionamento no ambiente de negócio. Essas serão ações de vital importância para a criação de valor às partes interessadas.

A gestão da cadeia de suprimentos apresenta-se, no ambiente de negócios, como uma ferramenta que permite ligar o mercado, a rede de distribuição, o processo de produção e a atividade de compra de tal modo que os consumidores tenham um alto nível de serviço ao menor custo total, simplificando, assim, o complexo processo de negócios e ganhando em eficiência (BOWERSOX; CLOSS; COOPER, 2006). De acordo com Ballou (2006), a gestão da cadeia de suprimentos se refere à integração de todas as atividades associadas à transformação e ao fluxo de bens 
e serviços, desde as empresas fornecedoras de matéria-prima até o usuário final, incluindo o fluxo de informação necessário para o sucesso.

Diante dessa necessidade de estabelecer relacionamentos estratégicos, Brito e Berardi (2010) destacam uma crescente demanda em integrar questões ambientais e sociais à gestão da cadeia de suprimentos por meio de pressões externas aos negócios. Para Pagell e Wu (2009), os estudos existentes até então não abordam os modelos de negócios e processos de decisão subjacentes à gestão sustentável da cadeia de abastecimento. $\mathrm{O}$ entendimento desses modelos e processos poderá auxiliar as organizações a gerenciarem a dinâmica intrínseca e as prioridades concorrentes entre as empresas e as metas socioambientais.

De acordo com Seuring (2011), a Gestão Sustentável da Cadeia de Suprimentos compreende a gestão dos fluxos de informação, material e capital, bem como a cooperação entre as empresas ao longo da cadeia, integrando as metas de todas as três dimensões do desenvolvimento sustentável, ou seja, econômico, ambiental e social, derivadas das mais diversas partes interessadas nas empresas que compõem uma cadeia produtiva. Na Sustainable Supply Chain Management (SSCM ), critérios ambientais e sociais precisam ser cumpridos pelos membros dentro da cadeia de suprimentos, enquanto se espera que a competitividade seja mantida, satisfazendo as necessidades das partes interessadas.

Uma cadeia de suprimentos sustentável reflete a capacidade da empresa para planejar, mitigar, detectar, responder e se recuperar de potenciais riscos globais. Esses riscos envolvem a comercialização, o desenvolvimento do produto, a seleção de canais, as decisões de mercado, o abastecimento, a complexidade de transporte, a regulação do Governo e do setor, a disponibilidade de recursos, a gestão de talentos e as plataformas alternativas de energia e segurança (CLOSS; SPEIER; MEACHAN, 2011).

Para Seuring e Muller (2008), a SSCM apresenta três aspectos que a distinguem da SCM: demanda que se examine um número maior de impactos em uma cadeia de suprimento estendida; considera um grupo mais numeroso de objetivos de desempenho em razão da inserção das dimensões ambiental e social da sustentabilidade; e, apresenta maior necessidade de integração e cooperação entre membros da cadeia de suprimento.

Pagell e Wu (2009) sugerem que as práticas que direcionam a uma cadeia de suprimentos mais sustentável são as melhores na gestão tradicional da cadeia de suprimentos, acrescentando novos comportamentos. Segundo esses autores, a capacidade de inovação está associada à sustentabilidade. Assim, a capacidade organizacional para inovar é, então, um precursor para a gestão sustentável bemsucedida da cadeia de suprimentos. 
Outro atributo organizacional considerado um precursor para a gestão sustentável da cadeia de suprimentos é a orientação gerencial. A literatura sugere que as empresas precisam ser proativas e comprometidas. Ser proativo e comprometido somente pode ser eficaz se o modelo de negócio e os elementos ambientais e sociais de sustentabilidade estiverem devidamente alinhados com a cadeia produtiva (PAGELL; WU, 2009). Com base em seus estudos, Pagell e Wu (2009) sugerem um modelo de práticas para Sustainable Supply Chain Management, o qual se mostra baseado tanto em aspectos relacionados à integração de metas de sustentabilidade às práticas e atividades cotidianas de SCM quanto em novos comportamentos adotados em cadeias sustentáveis, que as conduzem a um bom desempenho em todas as dimensões do TBL.

Entre os novos comportamentos identificados em SSCM, Pagell e Wu (2009) apontam dois grupos:

a) uma nova conceituação da cadeia de suprimento, referente às partes interessadas, além de fornecedores diretos e clientes (ex: ONGs, governos, comunidades ou concorrentes diretos);

b) um direcionamento explícito na continuidade da base de fornecedores, buscando uma base estável e capaz de atender às demandas da cadeia de suprimento por meio das seguintes práticas: transparência, rastreabilidade, certificação e descomoditização, além de iniciativas de desenvolvimento de fornecedores.

Uma característica verificada nas empresas analisadas por Pagell e Wu (2009) é o alinhamento por meio da internalização das metas de sustentabilidade ao negócio de forma que o desempenho não econômico (entenda-se, social e ambiental) se torna um fator crítico de crescimento da organização e do seu desempenho financeiro. Uma vez inseridas no negócio, são repassadas também à cadeia de suprimento.

\section{AVALIAÇÃO DO DESEMPENHO INOVADOR EM PROCESSOS}

O processo de inovação possui papel fundamental nas estratégias de crescimento para entrar em novos mercados, ampliar poder mercadológico e proporcionar à empresa uma vantagem competitiva. Motivadas pelo aumento da concorrência nos mercados globais, as empresas começaram a entender a 
importância da inovação, uma vez que, rapidamente, mudança de tecnologias e de competição global intensa corrói o valor acrescentado aos produtos e serviços existentes (GUNDAY et al., 2011).

De acordo com o Manual de Oslo (ORGANIZAÇÃO PARA A COOPERAÇÃO E DESENVOLVIMENTO ECONÔMICO, 2007), estudos sobre inovação e discussões de políticas enfatizam a importância de se considerar a inovação partindo de uma perspectiva ampla. Uma visão fundamentada em conhecimento concentra-se nos processos interativos por meio dos quais o conhecimento é criado e trocado internamente e entre outras organizações. Ainda segundo o Manual de Oslo, podem ser introduzidos nas empresas quatro tipos diferentes de inovação, como inovação de produto, de processo, de marketing e inovação organizacional. Inovações de produto e processo estão intimamente relacionadas ao conceito de evolução tecnológica (ORGANIZAÇÃO PARA A COOPERAÇÃO E DESENVOLVIMENTO ECONÔMICO, 2007) .

A inovação de processo é a implementação de uma nova produção ou significativa melhora no método de entrega. Isso inclui alterações significativas nas técnicas, nos equipamentos e/ou softwares. As inovações de processo podem ter a intenção de diminuir os custos unitários de produção ou entrega para aumentar a qualidade, ou para produzir ou entregar produtos novos ou significativamente melhorados (ORGANIZAÇÃO PARA A COOPERAÇÃO E DESENVOLVIMENTO ECONÔMICO, 2007).

No âmbito da gestão das inovações em processos, o resultado depende, entre outras variáveis, da habilidade do desenvolvimento e da implementação do processo da inovação incremental contínua. Nesse processo, eventualmente ocorrem melhorias significativas, como a adequação a uma nova geração de equipamentos, a automação industrial e a informatização de processos. Contudo, a evolução contínua das melhorias é que condicionará o êxito de tais propósitos (BESSANT; TIDD, 2009).

Grande parcela das pesquisas sobre inovação reconhece que a atividade inovadora é muito complexa e, consequentemente, difícil de ser mensurada, portanto, cria-se um grande desafio para pesquisadores que tentam entender os seus determinantes (MAKKONEN; VAN DER HAVE, 2012). Muitos estudos utilizam um único indicador, como $\mathrm{P} \& \mathrm{D}$, patentes, citações de patentes ou anúncios de novos produtos, argumentando que o indicador específico aplicado tem deficiências a menos que os outros indicadores.

Diante dessas dificuldades, Makkonen e Van Der Have (2012) sugerem outra forma de medição para a inovação com a aplicação de índices de inovação compostos, 
introduzidos pela primeira vez na década de 1990 para a medição de nível de inovação de empresas. Como havia muitos indicadores de inovação, os pesquisadores argumentam que cada indicador individual é apenas uma indicação parcial do esforço de inovação total realizado. Diante disso, alguns autores pioneiros afirmam que os índices de inovação são superiores a qualquer variável única sobre inovação.

Para Gunday et al. (2011), o desempenho inovador é a combinação de resultados globais da organização, como resultado de renovação e melhoria, esforços feitos considerando vários aspectos inovadores da empresa, entre eles, processos, produtos e estrutura organizacional. Dessa forma, destacam que o desempenho inovador é uma construção composta com base em vários indicadores de desempenho relativos, por exemplo, novas patentes, anúncios de novos produtos, projetos, processos e novos arranjos organizacionais.

Os autores sugerem variáveis que possam indicar o desempenho inovador em produtos e processos. Essas variáveis foram utilizadas para explorar os efeitos das inovações organizacionais, de processo, de produto e de marketing sobre os diferentes aspectos do desempenho da empresa, incluindo performances inovadoras, mercado, produção e finanças.

Gunday et al. (2011) concluem que a inovação de produto aparece como um fator crítico para o desempenho inovador, pois esse tipo de inovação atua como uma ponte, levando impactos positivos das inovações de processo para o desempenho inovador. Por essas razões, os gestores devem investir mais na capacidade de inovação e apoiar novas tentativas de introdução de inovações, tanto em produto e processo quanto na estrutura organizacional.

Avaliando as inovações em processo, quando contribuem e alavancam a produtividade, a organização pode adquirir uma vantagem de custo sobre a concorrência, permitindo uma margem sobre custos mais elevados para o preço de mercado prevalecente ou, dependendo da elasticidade da demanda, o uso de uma combinação de menor preço e maior margem sobre custos em comparação com a concorrência, para aumentar sua fatia de mercado e seu retorno (ORGANIZAÇÃO PARA A COOPERAÇÃO E DESENVOLVIMENTO ECONÔMICO, 2007).

Os resultados constatados pelo estudo de Gunday et al. (2011) substanciam o modelo conceitual proposto pelos autores e oferecem várias implicações gerenciais. Primeiro, os gerentes das empresas devem enfatizar mais as inovações, tendo nelas os mais importantes instrumentos para alcançar um comportamento competitivo sustentável. Segundo, melhorar o desempenho inovador depende do grau de implementação das inovações. 
Com base nos achados teóricos fundamentados pelos estudos e modelos teóricos propostos por Pagell e Wu (2009), os quais enfatizam a necessidade e a importância de gestão sustentável das cadeias de suprimento e, pelos estudos de Makkonen e Van Der Have (2012) e Gunday et al. (2011), que tratam do desempenho inovador como potencial de vantagens competitivas no ambiente atual, e considerando o problema de pesquisa proposto, com os conceitos referenciais elencados, tem-se a proposição de que a integração da sustentabilidade na gestão da cadeia de suprimentos está associada à inovação em processos na indústria mineral.

\section{MÉTODO DO ESTUDO}

O estudo possui natureza qualitativa e, quanto aos objetivos propostos, caracteriza-se como exploratório, pois sua intenção era proporcionar ao pesquisador maior conhecimento sobre determinado fenômeno, no qual o pesquisador parte de pressupostos e hipóteses e aprofunda seus estudos nos limites de uma realidade específica, buscando antecedentes e conhecimentos para torná-lo explícito (TRIVIÑOS, 2007).

Como estratégia de pesquisa, utilizou-se o método de estudo de caso, com o objetivo de descrever as práticas de gestão sustentável e o desempenho inovador em processos em uma empresa que faz parte da cadeia de suprimentos da indústria de alumínio. De acordo com Yin (2005, p. 32), “[...] um estudo de caso é uma investigação empírica que investiga um fenômeno contemporâneo dentro de seu contexto da vida real, especialmente quando os limites entre o fenômeno e o contexto não estão claramente definidos.”

As técnicas utilizadas para a coleta dos dados foram entrevista semiestruturada e pesquisa documental. O protocolo utilizado para a entrevista foi elaborado a partir dos pressupostos teóricos, com escopo na gestão para a sustentabilidade e na inovação em processos, o qual buscou identificar as condições que favorecem a integração da sustentabilidade na gestão da cadeia de suprimentos e sua associação com a inovação de processos. A pesquisa documental em relatórios e publicações em mídias foi utilizada neste estudo com o objetivo de subsidiar e enriquecer os dados coletados por meio das entrevistas.

O modelo conceitual para o estudo foi desenvolvido a partir da fundamentação teórica, com base nos estudos desenvolvidos por Pagell e Wu (2009); Makkonen e Van Der Have (2012) e Gunday et al. (2011), conforme ilustra o Diagrama 1. 
Diagrama 1 - Modelo conceitual desenvolvido para o estudo

\begin{tabular}{|c|c|}
\hline $\begin{array}{c}\text { Gestão Sustentável da Cadeia } \\
\text { de Suprimentos }\end{array}$ & $\begin{array}{l}\text { Desempenho inovador em } \\
\text { processos }\end{array}$ \\
\hline $\begin{array}{l}\text { - Práticas de gestão sustentável } \\
\text { das empresas na cadeia de } \\
\text { suprimentos } \\
\text { - Práticas internas à empresa } \\
\text { - Práticas envolvendo os } \\
\text { fornecedores (operações } \\
\text { externas - backward) }\end{array}$ & $\begin{array}{l}\text { - Inovação em processos } \\
\text { - Pesquisa e Desenvolvimento } \\
\text { - Patentes e Certificações } \\
\text { - Valor não adicionado a atividades de } \\
\text { produção } \\
\text { - Redução de custos variáveis } \\
\text { - Valor não adicionado a atividades de } \\
\text { entrega } \\
\text { - Redução do susto variável em } \\
\text { processos de logística } \\
\text {-Velocidade de entrega em processos } \\
\text { de logística } \\
\text { - Capacidade de inovação } \\
\text { - Capital humano } \\
\text { - Infraestrutura } \\
\text { - Mercado }\end{array}$ \\
\hline Pagell e Wu (2009) & $\begin{array}{c}\text { Makkonen e Van Der Have (2012), } \\
\text { Gunday et al. (2011) }\end{array}$ \\
\hline
\end{tabular}

Fonte: adaptado de Pagell e Wu (2009), Makkonen e Van Der Have (2012) e Gunday et al. (2011).

A entrevista foi realizada no primeiro trimestre de 2013 com o executivo responsável em atender aos interessados externos. A empresa foi selecionada pelo critério de escolha, acessibilidade, disponibilidade e interesse da empresa.

Para a análise dos dados, utilizou-se o método de análise de conteúdo, que, segundo Moraes (1999), consiste em uma técnica para a leitura e a interpretação do conteúdo de materiais oriundos de comunicação verbal ou não verbal. Para Bardin (2011, p. 47), a análise de conteúdo é caracterizada por

$$
\begin{aligned}
& \text { [...] um conjunto de técnicas de análise das comunicações vi- } \\
& \text { sando a obter, por procedimentos sistemáticos e objetivos de } \\
& \text { descrição do conteúdo das mensagens, indicadores (quantita- } \\
& \text { tivos ou não) que permitam a inferência de conhecimentos re- } \\
& \text { lativos às condições de produção/recepção (variáveis inferidas) } \\
& \text { destas mensagens. }
\end{aligned}
$$

Partindo desses pressupostos e a partir das questões definidas a priori, foram analisados os dados obtidos extraindo significados das mensagens resultantes da entrevista, buscando, assim, uma melhor compreensão das evidências. A análise dos dados inerentes à pesquisa documental pautou-se em verificar os conteúdos que de alguma forma representavam ou expressavam práticas inerentes à gestão sustentável e às ações que representassem evidências quanto ao desempenho inovador nos processos da empresa objeto deste estudo. 


\section{CARACTERIZAÇÃO DA EMPRESA ALUMÍNIO}

A empresa Alumínio é considerada líder mundial em laminados e também a maior recicladora de alumínio no mundo, ela transforma as qualidades inerentes do alumínio em componentes com design inovador para a criação de bens de consumo de alta demanda, e propõe produtos com inovação direcionada ao cliente e compromisso com a sustentabilidade.

É conhecida por projetar produtos e soluções de alumínios mais sofisticados e avançados do mundo atual; seus produtos e soluções atendem aos mercados, como embalagens, indústria automotiva e transporte, arquitetura e construção civil, litografia e impressão, aplicações industriais e bens de consumo eletrônicos.

Atualmente, no Brasil, a empresa produz bobinas de alumínio e produtos para os mercados de embalagem de bebidas e alimentos, construção civil, transporte e indústria. As unidades produtivas em atividades no país e suas respectivas localizações são apresentadas no Quadro 1.

Quadro 1 - Localização das unidades produtivas no Brasil

\begin{tabular}{|l|l|}
\hline Localização & Características da produção \\
\hline $\begin{array}{l}\text { Pindamonhangaba, } \\
\text { SP }\end{array}$ & $\begin{array}{l}\text { Produção de lâminas de alumínio para abastecer os segmentos de } \\
\text { embalagem, automotivo e de construção civil. Centro de recicla- } \\
\text { gem com capacidade de reciclagem de } 80 \text { mil toneladas por ano. }\end{array}$ \\
\hline $\begin{array}{l}\text { Santo André / } \\
\text { Utinga, SP }\end{array}$ & $\begin{array}{l}\text { Laminadora abastece os segmentos automotivo e de bens de consu- } \\
\text { mo em toda a América Latina. }\end{array}$ \\
\hline Ouro Preto, MG & $\begin{array}{l}\text { Processo completo - desde a extração de bauxita até a produção de } \\
\text { alumínio primário na forma de chapa e lingote, fábrica de celulose } \\
\text { e usinas de energia. }\end{array}$ \\
\hline
\end{tabular}

Fonte: Empresa Alumínio (2013a).

A empresa Alumínio desenvolve suas operações fundamentadas na abordagem de ciclo de vida do produto, considerada pela empresa uma abordagem fundamental para a sustentabilidade. O alumínio pode ser reciclado para produzir o mesmo produto infinitas vezes. Diferentemente de outros materiais comumente reciclados, como o papel, a utilização de alumínio reciclado não afeta a qualidade do produto. A empresa desenvolve uma cadeia de valor tipo "berço a berço", fabricando novos produtos a partir dos velhos.

É considerada líder mundial em reciclagem de alumínio e tem como meta reciclar 80\% dos resíduos de alumínio até o ano 2020. A empresa recicla tanto sucata de alumínio nova (da produção de liga e de alumínio) quanto velha (pós-consumo) 
de várias fontes e mercados. No Brasil, opera com cerca de 1700 colaboradores, sendo considerada uma grande empresa, com base em seu faturamento anual de aproximadamente $\mathrm{R} \$ 2,6$ bilhões em 2012.

\section{ANÁLISE E DISCUSSÃO DOS RESULTADOS}

As práticas de gestão sustentável na cadeia de suprimentos e o desempenho inovador em processos foram analisados a partir de duas dimensões e cinco categorias de análise, conforme apresentado no Quadro 2.

Quadro 2 - Dimensões e categorias de análises

\begin{tabular}{|l|l|}
\hline Dimensões de análise & Categorias de análise \\
\hline \multirow{3}{*}{$\begin{array}{l}\text { Práticas de gestão sustentável na } \\
\text { cadeia de suprimentos }\end{array}$} & Práticas realizadas no ambiente interno da empresa \\
\cline { 2 - 2 } & Práticas externas envolvendo fornecedores \\
\cline { 2 - 2 } & Práticas externas envolvendo clientes \\
\hline \multirow{2}{*}{ Desempenho inovador } & Inovação em processos \\
\cline { 2 - 2 } & Capacidade de inovação \\
\hline
\end{tabular}

Fonte: adaptado de Pagell e Wu (2009), Makkonen e Van Der Have (2012) e Gunday et al. (2011).

\section{1 PRÁTICAS INTERNAS DE GESTÃO SUSTENTÁVEL}

As principais evidências encontradas referentes às práticas de gestão sustentável na cadeia de suprimentos adotadas pela empresa Alumínio, no seu ambiente interno, são apresentadas no Quadro 3.

Quadro 3 - Práticas de gestão sustentável internas

\begin{tabular}{|l|l|}
\hline \multicolumn{2}{|l|}{ Práticas realizadas no ambiente interno da empresa } \\
\hline Práticas/Variáveis & Evidências \\
\hline & $\begin{array}{l}\text { "A companhia definiu Metas de Sustentabilidade que } \\
\text { deverão ser atingidas até 2020." } \\
\text { "Dentre as metas, estão incluídos: redução de 39\% do } \\
\text { consumo de energia elétrica e gás natural; redução em }\end{array}$ \\
$\begin{array}{l}\text { Comprometimento proativo } \\
\text { referente às práticas de gestão } \\
\text { sustentável }\end{array}$ & $\begin{array}{l}50 \% \text { das emissões de GHG (gases do efeito estufa); } \\
\text { redução em 25\% do consumo de água; zerar o volume de } \\
\text { resíduo enviado para aterros; e 80\% de conteúdo reciclado } \\
\text { no produto final." } \\
\text { "[...], além disso, são definidas iniciativas estratégicas } \\
\text { (objetivos e metas) para cada planta para que programas } \\
\text { de melhoria sejam implantados anualmente. ” }\end{array}$ \\
\hline
\end{tabular}




\begin{tabular}{|c|c|}
\hline $\begin{array}{l}\text { Integração do desenvolvi- } \\
\text { mento sustentável no proces- } \\
\text { so de tomada de decisões }\end{array}$ & $\begin{array}{l}\text { "Todos os indicadores de desempenho de Sustentabili- } \\
\text { dade são acompanhados periodicamente pela alta direção } \\
\text { da companhia para que as tomadas de decisão estejam } \\
\text { atreladas ao desenvolvimento sustentável, foco principal } \\
\text { de nossa operação." } \\
\text { "Para dar suporte a essa estratégia, Centros de Coleta foram } \\
\text { instalados em seis cidades no Brasil para captar a lata de alumí- } \\
\text { nio de forma mais rápida." }\end{array}$ \\
\hline $\begin{array}{l}\text { Integração de esforços para } \\
\text { práticas ambientais e sociais }\end{array}$ & $\begin{array}{l}\text { "Com relação ao social, a empresa possui o programa [...] que, } \\
\text { sob a ótica da política de Responsabilidade Social, apoia pro- } \\
\text { jetos que tem como foco de atuação a Segurança (estendendo } \\
\text { para a comunidade o nosso compromisso com a seguran- } \\
\text { ça), a Reciclagem (promovendo ações cujo objetivo seja a } \\
\text { reciclagem) e a Educação (voltada para as áreas de ciências e } \\
\text { matemáticas)." }\end{array}$ \\
\hline $\begin{array}{l}\text { Sistemas de mensuração das } \\
\text { práticas gerenciais adotadas } \\
\text { em prol da sustentabilidade }\end{array}$ & $\begin{array}{l}\text { "Cada planta possui um sistema de mensuração e consoli- } \\
\text { dação do monitoramento." } \\
\text { "[...] periodicamente, os resultados são compilados e } \\
\text { divulgados através de Relatório de Sustentabilidade Cor- } \\
\text { porativo." }\end{array}$ \\
\hline $\begin{array}{l}\text { Práticas ou sistemas de } \\
\text { Gestão da Qualidade Total, } \\
\text { Produção Enxuta, etc. }\end{array}$ & $\begin{array}{l}\text { "Sim, possui sistema de gestão da qualidade ISO } \\
\text { 9001:2008, e nossa produção segue metodologia Lean." }\end{array}$ \\
\hline $\begin{array}{l}\text { Desenvolvimento do capital } \\
\text { humano }\end{array}$ & $\begin{array}{l}\text { "A empresa desenvolve o seu capital humano, pois acre- } \\
\text { dita que através do desenvolvimento de nossos profissio- } \\
\text { nais, atingiremos nossos objetivos de negócio e teremos } \\
\text { pessoas mais capacitadas e engajadas com nosso plano de } \\
\text { crescimento." } \\
\text { "Além desse Plano, também investimos de forma co- } \\
\text {-participativa em cursos de MBA, Pós-graduação e cursos } \\
\text { de idiomas." }\end{array}$ \\
\hline $\begin{array}{l}\text { Alinhamento da gestão } \\
\text { sustentável ao modelo de } \\
\text { negócio }\end{array}$ & $\begin{array}{l}\text { "Na empresa, as metas ambientais e sociais estão orien- } \\
\text { tando as prioridades econômicas. Só no último ano fiscal, } \\
\text { compreendido entre abril/2011 e março/2012, [...] fize- } \\
\text { mos melhorias muito positivas nas iniciativas de susten- } \\
\text { tabilidade, além de se lançar as bases para alcançar nossas } \\
\text { metas para 2020." }\end{array}$ \\
\hline $\begin{array}{l}\text { Valores ou critérios adotados } \\
\text { pela empresa são semelhan- } \\
\text { tes aos valores e critérios } \\
\text { adotados por seus parceiros } \\
\text { (fornecedores e clientes) }\end{array}$ & $\begin{array}{l}\text { "A empresa espera que seus fornecedores conheçam e } \\
\text { sigam os padrões éticos e de sustentabilidade estabeleci- } \\
\text { dos pela empresa. [...] esses princípios estão descritos no } \\
\text { código de conduta de fornecedores." }\end{array}$ \\
\hline
\end{tabular}




\begin{tabular}{|l|l|}
\hline Estratégias de avaliação e \\
periódica & $\begin{array}{l}\text { "A empresa mantém o canal de diálogo aberto com as } \\
\text { comunidades nas quais está inserida." } \\
\text { "Seguimos à risca os padrões exigidos pelos órgãos am- } \\
\text { bientais e, dentro disso, são realizados monitoramentos } \\
\text { constantes dos efluentes, ruídos, emissões atmosféricas } \\
\text { que, em função do processo produtivo, são emitidos pela } \\
\text { empresa." }\end{array}$ \\
\hline $\begin{array}{l}\text { Análise dos componentes } \\
\text { que integram sua cadeia de } \\
\text { suprimentos }\end{array}$ & $\begin{array}{l}\text { "Sim, existe um processo de seleção e avaliação de for- } \\
\text { necedores e clientes que permite analisar e classificar os } \\
\text { interessados que eventualmente possam vir a ter relação } \\
\text { com a empresa." }\end{array}$ \\
\hline
\end{tabular}

Fonte: os autores.

As variáveis utilizadas pelo modelo conceitual deste estudo quanto a práticas internas de gestão revelam que a empresa Alumínio tem direcionado esforços estratégicos e operacionais em prol da sustentabilidade em sua cadeia de suprimentos. Entre as variáveis verificadas, as evidências destacam a postura e o comprometimento proativo da empresa em elaborar um plano com objetivos, metas e sistemas de mensuração de desempenho das ações, e em integrar o desenvolvimento sustentável no processo de tomada de decisões.

No ambiente interno, ainda são destacados os sistemas de gestão de qualidade da produção, que, de acordo com Pagell e Wu (2009), são essenciais para a implantação de práticas que visem a uma gestão mais sustentável na cadeia de suprimentos. Destaca-se, também, a adoção de códigos de conduta para os fornecedores, os quais provocam um engajamento maior das partes interessadas com a sustentabilidade.

Quantoàvariável transparência no tratamentoe disponibilidade de informações para a cadeia de suprimentos, verificou-se, no relatório de sustentabilidade da empresa Alumínio, que uma das principais áreas de foco no ano 2012 consistiu em comunicar e interagir com os seus colaboradores sobre o compromisso com a sustentabilidade. O objetivo dessa estratégia buscava orientar os colaboradores sobre a abordagem para a sustentabilidade e como eles podem contribuir para os esforços empreendidos pela empresa.

O relatório ainda ressalta que a empresa tem aumentado significativamente as ações de comunicações internas usando briefings de gestão, publicações da empresa, intranet e outras mídias. As evidências revelam que a empresa Alumínio tem empreendido esforços na construção de uma maior consciência da sustentabilidade 
entre os seus colaboradores e destacam que a intenção é incorporar totalmente a sustentabilidade na cultura da empresa.

A estratégia em manter avaliações periódicas com o objetivo de avaliar os impactos da atividade empresarial nos ecossistemas e comunidades também é uma ação que pode contribuir para uma gestão mais sustentável na cadeia produtiva. De acordo com a Gestora entrevistada, "A empresa mantém o canal de diálogo aberto com as comunidades nas quais está inserida [...] com isso, conseguimos obter parâmetros exatos de como a nossa atividade está ou não impactando o meio ambiente e a comunidade do entorno.” (informação verbal). Essas evidências indicam que a empresa vem adotando essa prática.

Outra variável que se destacou em sua análise foi a avaliação dos componentes que integram sua cadeia de suprimentos. De acordo com a gerência de comunicação externa, existe um processo de seleção e avaliação que permite analisar e classificar os interessados que eventualmente possam vir a ter relação com a empresa.

Consultando as políticas de gestão da empresa disponíveis em seu site no sentido de corroborar com as afirmações da gestora entrevistada, verificou-se que o engajamento das partes interessadas é um componente essencial da gestão sustentável consistente com uma abordagem de ciclo de vida, no qual o compromisso é trabalhar para entender e responder a toda a gama de interessados que são impactados em toda a cadeia produtiva do alumínio.

A empresa Alumínio atua com seus stakeholders de forma contínua e por meio de uma variedade de fóruns e canais de comunicação. Em seu programa de Responsabilidade Social Empresarial (RSE), em 2012, a empresa esforçou-se para começar a implantar um processo mais formalizado em cada uma das instalações, visando à prática de diálogo com as organizações não governamentais, autoridades governamentais locais, de outras empresas e outros interessados da comunidade. O principal objetivo dessas ações é melhor identificar, compreender e resolver as questões mais importantes nas comunidades onde a empresa tem suas operações.

\section{2 PRÁTICAS EXTERNAS ENVOLVENDO FORNECEDORES}

As práticas externas com fornecedores da empresa Alumínio envolveram aspectos como processo de seleção, análise de riscos das fontes de suprimentos, decisão no processo de compra e fortalecimento da sustentabilidade na cadeia local. As evidências resultantes da entrevista são apresentadas no Quadro 4. 
Quadro 4 - Práticas externas envolvendo fornecedores

\begin{tabular}{|c|c|}
\hline \multicolumn{2}{|c|}{ Práticas realizadas envolvendo os fornecedores da empresa } \\
\hline Práticas/Variáveis & Evidências \\
\hline $\begin{array}{l}\text { Seleção, critérios e } \\
\text { desenvolvimento dos } \\
\text { fornecedores }\end{array}$ & $\begin{array}{l}\text { "Existe um processo de seleção que classifica os fornecedores de } \\
\text { acordo com sua importância e risco para a empresa. De acordo } \\
\text { com essa classificação, o fornecedor é submetido a uma análise } \\
\text { documental específica, que visa avaliar questões como o cumpri- } \\
\text { mento de legislação e a uma avaliação técnica que permite classifi- } \\
\text { car os fornecedores com relação ao nível de serviço." } \\
\text { "[...] em alguns casos, as certificações e documentações são } \\
\text { analisadas já no processo de qualificação. Em outros, isso pode ser } \\
\text { objeto de auditoria externa ao fornecedor." }\end{array}$ \\
\hline $\begin{array}{l}\text { Análise de riscos das } \\
\text { fontes de suprimen- } \\
\text { tos }\end{array}$ & $\begin{array}{l}\text { "A empresa analisa constantemente sua base de fornecedores e os } \\
\text { classifica de acordo com sua importância para o negócio. Através } \\
\text { desse processo, a empresa define quem são os parceiros críticos e es- } \\
\text { tratégicos e estabelece uma relação diferenciada com essas empresas." } \\
\text { "[...] esse processo é realizado periodicamente pelos gestores de } \\
\text { categorias de suprimentos." }\end{array}$ \\
\hline $\begin{array}{l}\text { Decisões de compra } \\
\text { (custo total ou pre- } \\
\text { ços) e descomoditi- } \\
\text { zação das entradas }\end{array}$ & $\begin{array}{l}\text { "Principalmente para as categorias que são classificadas como crí- } \\
\text { ticas e estratégicas, o preço não é o critério principal para a escolha } \\
\text { do fornecedor." }\end{array}$ \\
\hline $\begin{array}{l}\text { Fortalecer a susten- } \\
\text { tabilidade na cadeia } \\
\text { local }\end{array}$ & $\begin{array}{l}\text { "A empresa leva em conta o custo total da operação. Dessa forma, } \\
\text { os fornecedores locais têm uma vantagem competitiva pelo custo } \\
\text { de transporte menor. Porém, os critérios de qualidade e nível de } \\
\text { serviço precisam ser atingidos na sua integridade." }\end{array}$ \\
\hline
\end{tabular}

Fonte: os autores.

As evidências resultantes da análise do conteúdo da entrevista com a Gerência responsável revelam que a empresa adota a maioria das práticas elencadas pelo modelo conceitual deste estudo.

Quanto aos critérios adotados pela empresa referente à seleção e ao desenvolvimento de seus fornecedores, segundo a Gerência, a empresa adota um processo de seleção que classifica os fornecedores de acordo com sua importância e risco. Conforme essa classificação, o fornecedor é submetido a uma análise documental específica, que visa avaliar questões como o cumprimento de legislação, e a uma avaliação técnica, que permite classificar os fornecedores em relação ao nível de serviço, em alguns casos fazendo uso de auditorias externas com as fontes de suprimentos.

Avaliar os riscos inerentes às fontes de suprimentos também é uma prática considerada fundamental para a gestão sustentável na cadeia de suprimentos. As evidências indicam que a empresa Alumínio analisa constantemente sua base de fornecedores e os classifica de acordo com sua importância para o negócio. Por meio 
desse processo, a empresa define quem são os parceiros críticos e estratégicos e estabelece uma relação diferenciada com essas empresas.

Outra prática elencada por Pagell e Wu (2009) como variável sinalizadora de uma postura que contribui para uma gestão sustentável na cadeia de suprimentos é a adoção de estratégias de compra observando o custo total e não se preocupando somente com preços, ou seja, adota estratégias de descomoditização das entradas (adquire produtos com algo além do preço, considerando a negociação e o relacionamento com o fornecedor uma ação estratégica). $\mathrm{Na}$ empresa, essa prática é adotada para as categorias de suprimentos que são classificadas como críticas e estratégicas, então o preço não é o critério principal para a contratação do fornecedor.

Desenvolver estratégias para fortalecer a sustentabilidade na cadeia local, buscando firmar relações com fornecedores mais próximos com o objetivo de minimizar os custos com transportes, também foi uma variável considerada. Nesse aspecto, as evidências indicam que a empresa considera o custo total da operação na tomada de decisão. Com isso, os fornecedores locais têm uma vantagem competitiva pelo custo de transporte menor. Porém, conforme ressalta a gerência entrevistada, "[...] os critérios de qualidade e nível de serviço precisam ser atingidos na sua integridade."

Quanto às práticas externas que envolvem os fornecedores, Pagell e Wu (2009) concluíram, em seus estudos, que os gestores atuantes em cadeias de suprimentos sustentáveis tratarão a continuidade dos fornecedores como uma estratégia importante e reforçam que as práticas como descomoditização, transparência e desenvolvimento dos fornecedores não tradicionais fortalecem a continuidade e reduzem os riscos com as fontes de suprimentos.

\section{3 PRÁTICAS EXTERNAS ENVOLVENDO CLIENTES}

As práticas externas direcionadas aos clientes que visam a uma gestão sustentável da cadeia de suprimentos e as evidências resultantes da entrevista com a Gerência da empresa Alumínio são apresentadas no Quadro 5. 
Quadro 5 - Práticas de gestão sustentável envolvendo os clientes

\begin{tabular}{|l|l|}
\hline \multicolumn{2}{|l|}{ Práticas realizadas envolvendo os clientes da empresa } \\
\hline Práticas/Variáveis & Evidências \\
\hline $\begin{array}{l}\text { Ações que demonstrem } \\
\text { que a empresa está preo- } \\
\text { cupada com as questões } \\
\text { inerentes à sustentabili- } \\
\text { dade }\end{array}$ & $\begin{array}{l}\text { "Sim, [...] a maior evidência da preocupação da empresa } \\
\text { com a sustentabilidade foi o estabelecimento das Metas de } \\
\text { das operações." }\end{array}$ \\
\hline $\begin{array}{l}\text { Divulgação das práticas } \\
\text { inerentes à sustentabili- } \\
\text { dade }\end{array}$ & $\begin{array}{l}\text { "A empresa utiliza o relatório de sustentabilidade para divulgar } \\
\text { seus objetivos, metas e resultados." } \\
\text { "Este relatório é preparado de acordo com os princípios de ma- } \\
\text { terialidade, integralidade, equilíbrio, comparabilidade, exatidão, } \\
\text { confiabilidade, oportunidade e clareza." } \\
\text { "Aplicamos princípios de qualidade para a sua coleta de dados e o } \\
\text { processo de comunicação é baseado na Global Reporting Initiative." }\end{array}$ \\
\hline $\begin{array}{l}\text { Desenvolvimento da } \\
\text { transparência }\end{array}$ & $\begin{array}{l}\text { "A empresa demonstra a todos os interessados quais são as } \\
\text { expectativas com relação às práticas e padrões na gestão dos } \\
\text { negócios." }\end{array}$ \\
\hline $\begin{array}{l}\text { Práticas de desenvol- } \\
\text { vimento, utilização, } \\
\text { reutilização, reciclagem e } \\
\text { descarte dos produtos }\end{array}$ & $\begin{array}{l}\text { "Por se tratar de alumínio, um produto com reciclabilidade } \\
\text { infinita, parte de nosso volume de vendas retorna para nossa } \\
\text { operação em forma de retalho, devido a sobras no processo } \\
\text { de fabricação de latas de alumínio." }\end{array}$ \\
\hline chados (logística reversa) & $\begin{array}{l}\text { "A logística, classificada como inbound, é integrada com a } \\
\text { outbound, ou seja, o mesmo veículo utilizado para efetuar a } \\
\text { entrega de produtos acabados nos clientes, em parte dos casos } \\
\text { "O reutilizado para retornar com o retalho." } \\
\text { janelas de coleta e entrega, nas duas pontas. Não é utilizado } \\
\text { nem um software específico para esse acompanhamento, que é } \\
\text { realizado através de planilhas em Excel e troca de e-mails." }\end{array}$ \\
\hline
\end{tabular}

Fonte: os autores.

Nessa categoria de análise, buscou-se verificar se a empresa estabelece ações com seus clientes que demonstrem que a organização está preocupada com as questões inerentes à sustentabilidade. De acordo com a gerência entrevistada, "[...] a maior evidência da preocupação da empresa com a sustentabilidade foi o estabelecimento das Metas de Sustentabilidade que norteiam todas as decisões do negócio e das operações."

Com base nas políticas de gestão publicadas em seu site, a empresa Alumínio busca tratar seus clientes como um dos principais grupos de interessados, pois, segundo ela, esse grupo impulsiona a demanda por sustentabilidade, uma vez que não 
está apenas preocupado com práticas próprias da empresa, mas também interessado em se engajar para encontrar soluções compartilhadas para os desafios comuns.

Outra prática verificada pelas variáveis é como a organização desenvolve a transparência, demonstrando que corrobora com a sustentabilidade adotando práticas de gestão sustentável na sua cadeia produtiva. As evidências indicam que a empresa utiliza o Relatório de Sustentabilidade Anual para divulgar seus objetivos, metas e resultados. Os referidos relatórios são desenvolvidos de acordo com princípios de qualidade para a sua coleta de dados e processo de comunicação baseado na Global Reporting Initiative (GRI). Quando questionada sobre o desenvolvimento da transparência, a Gerência entrevistada ressaltou que a empresa demonstra a todos os interessados quais são as expectativas em relação às práticas e aos padrões na gestão dos negócios.

Buscando evidências que poderiam corroborar com os dados obtidos na entrevista, realizou-se uma análise documental no último Relatório de Sustentabilidade publicado pela empresa Alumínio em seu site.

Quanto à estratégia de sustentabilidade, a empresa ressalta, em seus relatórios, que a sustentabilidade está provocando uma mudança em seu mix de produtos e processos, como menor emissão de carbono, produtos que permitem aos clientes alcançarem seus objetivos de sustentabilidade por meio da leveza, aumento da reciclagem e outros benefícios do alumínio. A sustentabilidade também é o alvo da abordagem em busca da excelência em fabricação com ênfase em meio ambiente, saúde, segurança, e melhoria contínua na eficiência dos recursos.

O Relatório de Sustentabilidade busca demonstrar o progresso e a melhoria do desempenho. De acordo com o último relatório publicado, a empresa fez grandes progressos em muitos dos objetivos principais, incluindo o aumento da reciclagem de 33 para 39\% em apenas um ano, e fez progressos na meta de eficiência energética. Em alguns casos, porém, o progresso não aconteceu como programado.

Em 2011, foi estabelecido um conjunto de metas de sustentabilidade para a organização até 2020, utilizando a média dos anos fiscais de 2007 a 2009 como baseline. O Quadro 6 apresenta as médias de base para metas, resultados em 2011 e 2012, o progresso com referência à linha de base e as metas para o ano 2020. 
Quadro 6 - Conjunto de metas para a sustentabilidade em 2020 - empresa Alumínio

\begin{tabular}{|c|c|c|c|c|c|c|}
\hline \multirow{2}{*}{\multicolumn{2}{|c|}{\begin{tabular}{|l|} 
Objetivos \\
METAS GLOBAIS
\end{tabular}}} & \multirow{3}{*}{$\begin{array}{c}\text { Baseline } \\
\text { 2007/08 } \\
\begin{array}{l}\text { U\$ 0,6 } \\
\text { bilhões }\end{array}\end{array}$} & \multicolumn{3}{|c|}{ Desempenho } & \multirow{3}{*}{$\begin{array}{l}\text { Meta } \\
2020 \\
>\text { U\$ } \\
2,0 \\
\text { bilhões }\end{array}$} \\
\hline & & & \multirow{2}{*}{\begin{tabular}{|l|}
2011 \\
$\begin{array}{l}\text { U\$ 1,1 } \\
\text { bilhões }\end{array}$
\end{tabular}} & \multirow{2}{*}{\begin{tabular}{|l|}
2012 \\
U\$ 1,1 \\
bilhões
\end{tabular}} & \multirow{2}{*}{$\begin{array}{l}\begin{array}{l}\text { Pro- } \\
\text { gresso }\end{array} \\
>\end{array}$} & \\
\hline Rentabilidade & EBITDA & & & & & \\
\hline $\begin{array}{l}\text { Conteúdo } \\
\text { de metal } \\
\text { reciclado }\end{array}$ & $80 \%$ em 2020 & $30 \%$ & $33 \%$ & $39 \%$ & $>$ & $80 \%$ \\
\hline \multicolumn{7}{|c|}{ METAS OPERACIONAIS 2020} \\
\hline $\begin{array}{l}\text { Uso de } \\
\text { energia }\end{array}$ & $\begin{array}{l}\text { Reduzir em } 39 \% \text { por tone- } \\
\text { lada métrica de vendas }\end{array}$ & $\begin{array}{l}12,4 \mathrm{GJ} / \\
\mathrm{mt}\end{array}$ & $\begin{array}{l}10,5 \mathrm{GJ} / \\
\mathrm{mt}\end{array}$ & $\begin{array}{l}10,0 \mathrm{GJ} / \\
\mathrm{mt}\end{array}$ & $>$ & $\begin{array}{l}7,6 \mathrm{GJ} / \\
\mathrm{mt}\end{array}$ \\
\hline Uso da água & $\begin{array}{l}\text { Reduzir em } 25 \% \text { por tone- } \\
\text { lada métrica de vendas }\end{array}$ & $\begin{array}{l}3,7 \mathrm{~m} 3 \\
/ \mathrm{mt}\end{array}$ & $\begin{array}{l}3,1 \mathrm{~m} 3 / \\
\mathrm{mt}\end{array}$ & $\begin{array}{l}3,2 \mathrm{~m} 3 / \\
\mathrm{mt}\end{array}$ & $>$ & $\begin{array}{l}2,7 \mathrm{~m} 3 / \\
\mathrm{mt}\end{array}$ \\
\hline $\begin{array}{l}\text { Emissões de } \\
\text { GEE }\end{array}$ & $\begin{array}{l}\text { Reduzir para metade o } \\
\text { valor absoluto (Escopo } 1 \text {, } \\
2 \text { e } 3 \text { ) }\end{array}$ & $21 \mathrm{~m} \mathrm{mt}$ & $20 \mathrm{~m} \mathrm{mt}$ & $\begin{array}{l}19 \mathrm{~m} \\
\mathrm{mt}\end{array}$ & $>$ & $11 \mathrm{~m} \mathrm{mt}$ \\
\hline Aterro & $\begin{array}{l}\text { Zero resíduo em sistemas } \\
\text { de aterro }\end{array}$ & $60 \mathrm{~K} \mathrm{mt}$ & $52 \mathrm{~K} \mathrm{mt}$ & $49 \mathrm{~K} \mathrm{mt}$ & $>$ & $0 \mathrm{~K} \mathrm{mt}$ \\
\hline \multicolumn{7}{|c|}{ METAS EM RECURSOS HUMANOS 2020} \\
\hline Segurança & $\begin{array}{l}\text { Índice zero em acidentes } \\
\text { graves }\end{array}$ & 1,01 & 0,76 & 0,59 & $>$ & 0 \\
\hline \multirow[b]{2}{*}{$\begin{array}{l}\text { Colabora- } \\
\text { dores }\end{array}$} & $\begin{array}{l}100 \% \text { dos colaboradores } \\
\text { devem receber feedback de } \\
\text { desempenho anual }\end{array}$ & NA & $38 \%$ & $38 \%$ & $=$ & $100 \%$ \\
\hline & $\begin{array}{l}\text { Programa de desenvolvi- } \\
\text { mento (classe mundial) de } \\
\text { liderança, aferido no top } \\
10 \% \text { das empresas }\end{array}$ & NA & NA & $\begin{array}{l}\text { Em } \\
\text { pro- } \\
\text { gresso }\end{array}$ & $>$ & $\begin{array}{l}\text { Aferido } \\
\text { em mais } \\
\text { de } 10 \%\end{array}$ \\
\hline Comunidade & $\begin{array}{l}100 \% \text { das operações } \\
\text { implantarem processo de } \\
\text { desenvolvimento com a } \\
\text { comunidade local }\end{array}$ & NA & NA & $\begin{array}{l}\text { Em } \\
\text { pro- } \\
\text { gresso }\end{array}$ & $>$ & $100 \%$ \\
\hline $\begin{array}{l}\text { Código de } \\
\text { Conduta }\end{array}$ & $\begin{array}{l}\text { Códigos de funcionários e } \\
\text { fornecedores }\end{array}$ & NA & NA & $\begin{array}{l}\text { Em } \\
\text { pro- } \\
\text { gresso }\end{array}$ & $>$ & $100 \%$ \\
\hline
\end{tabular}

Fonte: Empresa Alumínio (2013b).

$(>)$ Melhoria ou a caminho de cumprir meta / $(=)$ Inalterado

Ainda de acordo com o Relatório de Sustentabilidade, em 2012 a empresa Alumínio tornou-se signatária do Pacto Global das Nações Unidas, uma iniciativa política importante para as empresas que estão comprometidas em alinhar suas operações e estratégias com os 10 princípios universalmente aceitos nas áreas de direitos humanos, trabalho, meio ambiente e anticorrupção. A empresa acredita que a participação nesse Pacto Global está alinhada na estratégia de sustentabilidade da empresa. 
De acordo com a declaração do Diretor de Sustentabilidade no Relatório de Sustentabilidade (2012), essas metas estão influenciando fortemente os investimentos de capital em como expandir dramaticamente a capacidade de reciclagem e aumentar a capacidade de produção de produtos com baixo carbono. O diretor ressalta ainda que a sustentabilidade está obrigando a empresa a repensar a tecnologia por trás de seus produtos e está mudando fundamentalmente o modelo de negócio.

Ainda de acordo com o Diretor de Sustentabilidade, nos anos 2011 e 2012, a empresa buscou aproximar-se a toda a base de clientes para aprender mais sobre os objetivos de sustentabilidade e como estes poderiam ajudar a empresa Alumínio a alcançá-los.

A postura adotada pela empresa Alumínio, a qual busca em seus clientes orientações que a auxiliem na adoção de estratégias e práticas de gestão mais sustentável, é corroborada por Miles, Munilla e Darroch (2009), os quais salientam que reconstruir um modelo de negócios para ambiente economicamente atraente com oportunidades baseadas em uma gestão sustentável requer uma reconsideração das suas capacidades e como a empresa pode criar novo valor para os seus clientes no âmbito de sua cadeia de suprimentos.

Para Dalé, Roldan e Hansen (2011), a gestão das práticas que envolvem os clientes deve considerar e avaliar variáveis não econômicas, demonstrando que a sustentabilidade tem importância para a parte jusante da cadeia de suprimentos, no entanto, os mesmos autores, com base nos resultados de seus estudos, ressaltam que essas práticas muito têm a evoluir na gestão que vise considerar essa parte interessada na cadeia produtiva.

\section{DESEMPENHO INOVADOR EM PROCESSOS}

As principais evidências encontradas no que se refere às ações que caracterizam desempenho inovador em processos da empresa são apresentadas no Quadro 7. 
Quadro 7 - Inovação em processos, variáveis e evidências

\begin{tabular}{|c|c|}
\hline \multicolumn{2}{|c|}{ Inovação em Processos } \\
\hline Ações/Variáveis & Evidências \\
\hline $\begin{array}{l}\text { Pesquisa e Desen- } \\
\text { volvimento }\end{array}$ & $\begin{array}{l}\text { "A inovação é a base da nossa estratégia e um fator crítico de nosso } \\
\text { crescimento. É também um dos componentes-chave para atingir o } \\
\text { nosso compromisso de ter } 80 \% \text { de conteúdo reciclado em todos os } \\
\text { nossos produtos em } 2020 \text { (uma de nossas Metas de Sustentabilida- } \\
\text { de)." } \\
\text { "Na América do Sul, também contamos com o Pinda Technology } \\
\text { Center (PTC), localizado na planta de Pindamonhangaba, SP e } \\
\text { cujos trabalhos são realizados com o alinhamento de informações e } \\
\text { metodologia com o Centro Global [...] para este Centro, anualmen- } \\
\text { te investimos cerca de R } \$ 1 \text { milhão." }\end{array}$ \\
\hline Patentes e marcas & $\begin{array}{l}\text { "Sim, a marca (nome da empresa) e o seu slogan 'Mais que alumí- } \\
\text { nio, Alumínio (nome da empresa)' são registrados." } \\
\text { "[...] este slogan reforça o posicionamento de marca da empresa que } \\
\text { demonstra que seu alumínio vai além do alumínio visto como uma } \\
\text { commodity, uma vez que traz consigo o emprego de alta tecnologia e } \\
\text { é classificado como um produto Premium." }\end{array}$ \\
\hline Certificações & $\begin{array}{l}\text { "Sim: Qualidade ISO 9001/ISO } 14001 \text { e ISO 18001." } \\
\text { "Essas certificações são um elemento do nosso esforço para padro- } \\
\text { nizar os sistemas de negócio, processos e procedimentos em todas } \\
\text { as nossas operações para alcançar consistentes e altos níveis de } \\
\text { desempenho." }\end{array}$ \\
\hline $\begin{array}{l}\text { Novos produtos e } \\
\text { serviços }\end{array}$ & $\begin{array}{l}\text { "A empresa trabalha na busca constante para atender às demandas de } \\
\text { seus clientes e se antecipar frente aos concorrentes." } \\
\text { "No mercado de chapas para latas, em conjunto com nossos clien- } \\
\text { tes, já lançamos diversos produtos inovadores [...] por exemplo, em } \\
2012 \text { introduzimos metal para a fabricação do King Can lata de } 24 \\
\text { oz." }\end{array}$ \\
\hline $\begin{array}{l}\text { Métodos e proces- } \\
\text { sos de trabalho }\end{array}$ & $\begin{array}{l}\text { "Sim, em } 2012 \text { várias inovações foram introduzidas em nossa planta } \\
\text { localizada em Pindamonhangaba, SP, por exemplo, nos Laminado- } \\
\text { res a Frio (Automatic Slow Down) para aumentar eficiência e proces- } \\
\text { sos de alta formabilidade do metal." }\end{array}$ \\
\hline $\begin{array}{l}\text { Adaptação dos } \\
\text { sistemas adminis- } \\
\text { trativos }\end{array}$ & $\begin{array}{l}\text { "Sim, em termos de softwares, por exemplo, desde } 2012 \text {, teve início } \\
\text { do processo de implantação do Sistema SAP que irá integrar todos } \\
\text { os processos financeiros das quatro regiões da empresa. O projeto } \\
\text { completo será finalizado até 2015." }\end{array}$ \\
\hline $\begin{array}{l}\text { Valores não } \\
\text { adicionados aos } \\
\text { processos, técnicas, } \\
\text { equipamentos e } \\
\text { sistemas }\end{array}$ & $\begin{array}{l}\text { "A empresa trabalha a partir da filosofia Lean Six Sigma, onde } \\
\text { projetos são abertos constantemente para eliminar ou simplificar } \\
\text { processos nas mais diversas áreas, desde áreas operacionais até } \\
\text { administrativas." }\end{array}$ \\
\hline
\end{tabular}




\begin{tabular}{|l|l|}
\hline $\begin{array}{l}\text { Gestão de custos } \\
\text { variáveis relaciona- } \\
\text { dos aos processos } \\
\text { de produção e à } \\
\text { logística de distri- } \\
\text { buição }\end{array}$ & $\begin{array}{l}\text { "Sigma, o sistema Gestão Inteligente de Custos (GIC) implantado } \\
\text { em } 2008 \text {, com a consultoria do Instituto INDG." } \\
\text { de custos, identificação dos GAPs e abertura de projetos de melho- } \\
\text { ria e ações para a entrega dos resultados esperados." }\end{array}$ \\
\hline $\begin{array}{l}\text { Eliminar os custos } \\
\text { variáveis em } \\
\text { processos relacio- } \\
\text { nados à logística de } \\
\text { distribuição }\end{array}$ & $\begin{array}{l}\text { "O custo de frete e armazenagem tem uma participação importante } \\
\text { na composição dos custos variáveis da organização [...] como medi- } \\
\text { dasimizar a utilização dos veículos/containers/vagões utilizados na na } \\
\text { maxeração in e outbound." }\end{array}$ \\
\hline $\begin{array}{l}\text { Velocidade relacio- } \\
\text { nada aos proces- } \\
\text { sos de logística e } \\
\text { distribuição }\end{array}$ & $\begin{array}{l}\text { "É essencial que a operação ligada ao processo de distribuição, como } \\
\text { carga e descarga, por exemplo, seja o mais produtiva possível." }\end{array}$ \\
\hline
\end{tabular}

Fonte: os autores.

As evidências indicam que a empresa Alumínio busca desenvolver produtos sustentáveis, por meio de um sistema contínuo de Pesquisa e Desenvolvimento (P\&D). Para incentivar inovações de sustentabilidade, a empresa possui infraestrutura de pesquisa em todas as plantas, por acreditar que a P\&D e a estratégia corporativa andam juntas, e estando fisicamente próximas, ajudarão a tornar isso possível.

Segundo a Gerente entrevistada, "[...] a inovação é a base da nossa estratégia e um fator crítico de nosso crescimento." Como exemplo, cita o Pinda Technology Center (PTC), localizado na planta de Pindamonhangaba, SP, onde os trabalhos são realizados com o alinhamento de informações e metodologia do Centro Global. Para esse Centro de Pesquisa, anualmente são investidos cerca de um milhão de reais.

Quanto às variáveis patentes, marcas e certificações, as evidências demonstram que a empresa é detentora de patentes e marcas e que busca manter um posicionamento de suas marcas como referência no mercado do alumínio em âmbito mundial. A empresa é detentora das certificações Gestão da Qualidade (ISO 9001:2008), Gestão Ambiental (ISO 14001) e Gestão de Saúde ocupacional e Segurança no trabalho (OHSAS 18001). De acordo com a Gerência entrevistada, “[...] essas certificações são um elemento do nosso esforço para padronizar os sistemas de negócio, processos e procedimentos em todas as nossas operações para alcançar consistentes e altos níveis de desempenho."

A introdução de inovações em processos de trabalhos e métodos também foi considerada uma variável que indica uma postura inovadora em processos. Segundo a Gerente entrevistada, no ano 2012 várias inovações foram introduzidas na planta 
localizada em Pindamonhangaba, SP e cita como exemplo a introdução dos laminadores a frio para aumentar a eficiência e os processos de alta formabilidade do metal.

Quanto à adaptação ou renovação dos sistemas administrativos de forma a se manter em sintonia com o ambiente, as evidências indicam que a empresa vem empreendendo esforços por meio da implantação de sistemas gerenciais baseados em tecnologia da informação, de modo a integrar todas as operações da empresa.

A estratégia em eliminar as atividades que não adicionem valor em seus processos e reduzir os componentes de custos variáveis em processo de produção, em técnicas, em equipamentos e sistemas de informação, é corroborada no sentido de que a empresa trabalha a partir da filosofia Lean Six Sigma, na qual os projetos são abertos constantemente para eliminar ou simplificar processos nas mais diversas áreas, desde as operacionais até as administrativas. A partir dessa filosofia, a empresa possui o sistema Gestão Inteligente de Custos (GIC), implantado em 2008.

A adoção de estratégias que buscam aumentar a velocidade em processos relacionados com a logística de distribuição, de acordo o modelo conceitual adotado, pode indicar uma postura inovadora em processos. De acordo com a Gerência entrevistada, esse tipo de prática é adotado, pois as operações pouco produtivas tornam o processo de distribuição caro, ineficiente e inflexível e impedem a utilização de modais mais baratos, como a cabotagem e o ferroviário, cujo trânsito é maior que o rodoviário e a disponibilidade é menor.

Visando corroborar com as evidências resultantes da entrevista, buscou-se elaborar uma análise nas políticas de gestão para a inovação em processos, disponíveis no site da empresa Alumínio.

A empresa declara que busca aplicar o conhecimento e a experiência do setor para encontrar soluções e desenvolver inovações nos processos que direcionam a excelência em suas operações. As principais orientações são para fornecer produtos consistentes e de alta qualidade e recursos exclusivos para os clientes, e tem como foco quatro diretrizes que buscam a inovação em seus processos:

a) a dinamização de unidades de fabricação críticas usando alterações nas etapas na eficiência do processo;

b) o aprimoramento do controle sobre a qualidade dos produtos;

c) a redução do descarte e da ineficiência da produção;

d) a melhoria da sustentabilidade dos processos. 
De acordo com a orientação para gestão da inovação, cada inovação no processo desenvolvida é analisada por uma equipe especializada, e os resultados são compartilhados com as outras instalações com necessidades semelhantes para passar por mais testes e avaliações. As inovações em processos que surgem desse compromisso colaborativo e rigoroso com a excelência na fabricação são implantadas em toda a empresa como "práticas recomendadas."

Para Bessant e Tidd (2009), as inovações em processos têm um papel estratégico nas organizações como fonte poderosa de vantagens competitivas, seja pela capacidade de desenvolver ideias e produtos que os concorrentes não conseguem seja por desenvolvê-los de forma diferenciada e com excelência. Diante das evidências apresentadas e do aporte teórico utilizado neste estudo, é possível concluir que a empresa Alumínio apresenta uma orientação estratégica e gerencial para a inovação, culminando em um desempenho significativo na inovação de seus processos.

\section{CAPACIDADE DE INOVAÇÃO}

As variáveis capital humano, mercado e infraestrutura, elencadas pelos estudos de Makkonen e Van Der Have (2012) como possíveis indicadores de capacidade de inovação das empresas, foram analisadas na empresa Alumínio. As evidências resultantes do conteúdo da entrevista são apresentadas no Quadro 8.

Quadro 8 - Capacidade de inovação, variáveis e evidências

\begin{tabular}{|c|c|}
\hline \multicolumn{2}{|l|}{ Capacidade de inovação } \\
\hline Ações/Variáveis & Evidências \\
\hline $\begin{array}{l}\text { Capital Humano } \\
\text { Disponibilidade } \\
\text { Aprendizagem e capa- } \\
\text { citação }\end{array}$ & $\begin{array}{l}\text { "De maneira geral, sim. Do ponto de vista da operação do ne- } \\
\text { gócio, eventualmente percebemos uma maior dificuldade em } \\
\text { posições mais técnicas, como engenheiros, técnico de manu- } \\
\text { tenção, eletricista. Mas não acreditamos que seja um problema } \\
\text { crônico." } \\
\text { "Sim, através do Plano Anual de Treinamento (focado em } \\
\text { aprimoramento de conhecimento técnico), custeio parcial de } \\
\text { MBA, Pós-graduação, idiomas, e também através de encontros } \\
\text { e workshops para desenvolvimento de comportamentos indivi- } \\
\text { duais ou da formação de times." }\end{array}$ \\
\hline
\end{tabular}




\begin{tabular}{|c|c|}
\hline $\begin{array}{l}\text { Mercado } \\
\text { Demanda futura } \\
\text { Tecnologia disponível }\end{array}$ & $\begin{array}{l}\text { "A empresa está pensando hoje nos produtos de amanhã. Os } \\
\text { nossos recursos de fabricação de laminados de alumínio pro- } \\
\text { duzem um produto leve, forte e flexível, tornando-o o material } \\
\text { ideal para uma série de aplicações hoje e no futuro." } \\
\text { "Verificamos uma demanda crescente, pois o alumínio repre- } \\
\text { senta o futuro de automóveis à arquitetura e componentes } \\
\text { eletrônicos para consumo." }\end{array}$ \\
\hline Infraestrutura & $\begin{array}{l}\text { "A atual infraestrutura logística no Brasil está aquém do que } \\
\text { demandamos. O exemplo mais forte fica por conta da disponi- } \\
\text { bilidade de malha ferroviária e, consequentemente, a disponi- } \\
\text { bilidade e nível de serviço que o modal oferece." } \\
\text { "Também nos deparamos com portos congestionados e com } \\
\text { infraestrutura, lentidão relacionada às questões aduaneiras e } \\
\text { alto custo, o que são complicadores." } \\
\text { "Faltam alternativas que poderiam ser utilizadas como ala- } \\
\text { vancas, para uma operação mais "lean" em todos os sentidos: } \\
\text { produtiva, sem desperdícios, mais barata e sustentável." }\end{array}$ \\
\hline
\end{tabular}

Fonte: os autores.

Quanto ao capital humano, verificaram-se aspectos sobre disponibilidade de mão de obra e capacidade de aprendizagem e capacitação desses recursos. As evidências revelam que a empresa Alumínio eventualmente tem dificuldades em obter recursos humanos no campo técnico relacionado às operações. Quanto à aprendizagem e à capacitação desses recursos, a empresa possui uma política de investimentos em seus colaboradores, fomentando a inovação e mantendo relacionamentos de alta qualidade com o mercado.

Quanto à variável mercado, de acordo com a Associação Brasileira do Alumínio (Abal), atualmente os Estados Unidos e o Canadá são os maiores produtores mundiais de alumínio. Entretanto, nenhum deles possui jazidas de bauxita em seu território, dependendo exclusivamente da importação. O Brasil tem a terceira maior reserva do minério no mundo, localizada na região amazônica, ficando atrás da Austrália e Guiné. Além da Amazônia, o alumínio pode ser encontrado no Sudeste do Brasil, na região de Poços de Caldas e Cataguases, MG. Diante desse contexto, a empresa visualiza uma demanda cada vez mais crescente, principalmente porque o alumínio estará cada vez mais inserido na produção de bens de consumo, desde automóveis até componentes eletrônicos.

Quanto à variável infraestrutura (meios de transporte, portos, aeroportos, comunicações) disponível para o desenvolvimento das operações da empresa em sua cadeia produtiva, as evidências indicam que, para a empresa, a atual infraestrutura logística no Brasil está aquém para o atendimento das demandas da empresa. De 
acordo com a Gerência entrevistada, "Faltam alternativas que poderiam ser utilizadas como alavancas, para uma operação mais 'Lean' em todos os sentidos: produtiva, sem desperdícios, mais barata e sustentável.”

\section{PRINCIPAIS CONCLUSÕES DO CASO}

Diante do conjunto de evidências resultantes da análise da entrevista concedida pela Gerência e pela análise de publicações disponíveis no site da empresa, é possível afirmar que a empresa Alumínio possui uma postura proativa com intenção de integrar a sustentabilidade em suas estratégias e nas relações com seus stakeholders, desenvolvendo uma cadeia de suprimentos que forneça à sociedade produtos à base de alumínio mais sustentáveis.

As práticas de gestão sustentável tanto internas quanto externas envolvendo fornecedores e clientes podem ser destacadas como ações efetivas na empresa Alumínio. Porém, cabe um destaque às práticas internas, o comprometimento proativo da empresa em elaborar um plano com objetivos, metas e sistemas de mensuração de desempenho das ações, integrando o desenvolvimento sustentável no processo de tomada de decisões. Quanto às práticas externas, salienta-se a postura da empresa em aproximar-se com toda a base de clientes, para aprender mais sobre os objetivos de sustentabilidade e como estes poderiam ajudar a alcançá-los.

A postura da empresa Alumínio converge com as ideias de Miles, Munilla e Darroch (2009), os quais consideram que, para empresas criarem vantagem competitiva no futuro, as questões de sustentabilidade tendem a emergir como dominantes no estímulo potencial que conduz as empresas a desenvolverem uma posição competitiva, reduzindo o desperdício e os custos e melhor satisfazendo as exigências de responsabilidade social em mercados-alvo ambientalmente orientados.

Quanto ao desempenho inovador em processos, o conjunto de evidências demonstra que a empresa tem uma postura inovadora em suas operações. A maioria das variáveis utilizadas pelo modelo proposto é corroborada pelas evidências. Diante dessas constatações, é possível afirmar que se identifica como uma empresa inovadora. Essa constatação pode ser destacada com os investimentos dispendidos pela empresa na área de Pesquisa e Desenvolvimento e pelas políticas de gestão para a inovação em processos já destacadas neste estudo, principalmente quando busca a colaboração dos parceiros na cadeia de suprimentos. 
Segundo Brito e Berardi (2010), o desempenho inovador está vinculado ao desenvolvimento da capacidade colaborativa. O aprendizado e a inovação gerados nas interações com stakeholders podem compor uma competência diferenciadora da empresa. Essa competência, na gestão das relações e nas trocas de conhecimento, pode ser aplicada mais amplamente pela empresa e vir a gerar ganhos a diversos componentes de uma cadeia de suprimentos sustentável.

Buscando associar as práticas de gestão sustentáveis adotadas no âmbito da cadeia de suprimentos e o desempenho inovador em processos, pode-se apontar que a adoção dessas práticas analisadas esteja colaborando para o desempenho inovador da empresa Alumínio. Essa constatação é corroborada pelas declarações do Diretor de Sustentabilidade da empresa, o qual enfatiza que integrar a sustentabilidade ao núcleo dos objetivos dos negócios ajudará a tornar o desempenho social, econômico e ambiental uma ideia mais ampla.

\section{CONSIDERAÇÕES FINAIS}

Em consequência das expectativas e pressões sociais, é notável uma evolução nos estudos e pesquisas que analisam fenômenos ligados à indústria mineral, no entanto, no Brasil, ainda são encontrados poucos estudos que buscam verificar o envolvimento das empresas do setor de alumínio com orientação para a gestão sustentável. Essa lacuna representou uma oportunidade para este estudo, considerando a importância desse setor industrial no desenvolvimento econômico brasileiro. $\mathrm{O}$ estudo em pauta teve como objetivo analisar e associar a gestão sustentável da cadeia de suprimentos com o desempenho inovador do processo produtivo em uma empresa do setor de alumínio.

Diante do conjunto de evidências constatadas, os principais resultados indicam que as práticas de gestão que configuram a formação de cadeias de suprimentos sustentáveis fazem parte do escopo estratégico do caso em tela. Quanto ao desempenho inovador e à capacidade de inovação em processos, os resultados verificados a partir das variáveis fundamentadas pelo modelo conceitual proposto revelam que a empresa apresenta um perfil inovador em seus processos.

Refletindo sobre os resultados deste estudo, é notável a complexidade que envolve os processos decisórios das organizações e suas relações com as diversas partes interessadas em suas cadeias de suprimento, pois esse novo contexto demanda novas formas de orientar as decisões. A concepção da Gestão Sustentável da Cadeia de 
Suprimentos permite, pela abrangência de seus conceitos, promover uma integração ainda maior do que possibilitava a perspectiva da SCM tradicional. Assim, essa nova abordagem pode servir como concepção estratégica ao desenvolvimento de processos ao longo de toda a cadeia, promovendo uma gestão social e ambientalmente correta e economicamente sustentável.

O método de estudo de caso foi adotado neste estudo por ser considerado o mais adequado para se atingir o objetivo. Embora não seja possível generalizar os resultados, dada a característica qualitativa do estudo, o desenvolvimento do caso permitiu confirmar a associação entre as variáveis, conforme proposto pelo modelo conceitual da pesquisa. Pode-se considerar, em razão das limitações dos estudos de caso, que houve uma confirmação da proposição desenvolvida, no entanto, as evidências encontradas não poderão ser extrapoladas para o universo considerado na pesquisa, restringindo-se apenas à empresa objeto deste estudo.

Para estudos futuros, sugere-se que se busque ampliar a amostra com o objetivo de aprofundar os resultados apresentados e permitir outras análises, visando encontrar fatores que expliquem o comportamento das empresas em relação ao fenômeno estudado. Desse modo, será possível proceder a outras análises, podendo, por exemplo, desenvolver um estudo com abordagem quantitativa, de modo a verificar a adoção de práticas de gestão sustentável na cadeia de suprimentos e sua influência no desempenho inovador em processos.

\section{REFERÊNCIAS}

BALLOU, R. H. The evolution and future of logistics and Supply Chain Management. Produção, v. 16, n. 3, p. 375-386, set./dez. 2006.

BARDIN, L. Análise de conteúdo. ed. rev. e ampl. São Paulo: Edições 70, 2011.

BESSANT, J.; TIDD, J. Inovação e empreendedorismo. Porto Alegre: Bookman, 2009.

BOWERSOX, D. J.; CLOSS, D. J.; COOPER, M. B. Gestão da Logística de suprimentos. Porto Alegre: Bookman, 2006.

BRITO, R. P.; BERARDI, P. C. Vantagem competitiva na gestão sustentável da cadeia de suprimentos: um meta estudo. Revista de Administração de Empresas, São Paulo, v. 50, n. 2, p. 155-169, abr./jun. 2010. 
CLOSS, D. J.; SPEIER, C.; MEACHAN, N. Sustainability to support end-to-end value chains: the role of supply chain management. Journal of the Academy of Marketing Science, v, 39, p. 101-116, 2011.

DALÉ, L. B. C.; ROLDAN, L. B.; HANSEN, P. B. Analysis of Sustainability Incorporation by Industrial Supply Chain in Rio Grande do Sul State (Brazil) Journal of Operations and Supply Chain Management, v. 4, n. 1 , p. 25-36, 2011.

ELKINGTON, J. Enter the triple bottom line. In: HENRIQUES, J.; RICHARDSON, J. (Org.). The triple bottom line, does it all add up? Assessing the sustainability of business and CSR. London: Earthscan, 2004. cap. 1, p. 1-16.

ELKINGTON, J. Sustentabilidade, canibais de garfo e faca. São Paulo: M. Books, 2011.

EMPRESA ALUMINIO. Ativos e Recursos: capacidade fabril. Disponível em: $<$ http://www.novelis.com/pt-br/Paginas/Assets-and-Capabilities.aspx> . Acesso em: 05 dez. 2013a.

EMPRESA ALUMINIO. Visão estratégica para a sustentabilidade: metas para a sustentabilidade até 2020. Disponível em: < http:/www.novelis.com/pt-br/ Paginas/Our-Vision-And-Strategy.aspx>. Acesso em: 10 nov. 2013 b.

GUNDAY, G. et al. Effects of innovation types on firm performance. International Journal Production Economics, v. 133, p. 662-676, 2011.

HART, S. L.; MILSTEIN, M. B. Creating sustainable value. Academy of Management Executive, v. 17, n. 2, p. 56-69, 2003.

MAKKONEN, T.; VAN DER HAVE, R. P. Benchmarking regional innovative performance: composite measures and direct innovation counts. Scientometrics, Budapest, Hungary, 2012.

MILES, M. P.; MUNILLA, L. S.; DARROCH, J. Sustainable corporate entrepreneurship. International Entrepreneurship and Management Journal, v. 5, p. 65-76, 2009.

MORAES, R. Análise de conteúdo. Revista Educação, Porto Alegre, v. 22, n. 37 , p. 7-32, 1999.

NASCIMENTO, E. P. Trajetória da sustentabilidade: do ambiental ao social, do social ao econômico. Estudos Avançados, v. 26, n. 74, p. 51-64, 2012. 


\section{ORGANIZAÇÃO PARA A COOPERAÇÃO E DESENVOLVIMENTO}

ECONÔMICO. Manual de Oslo: diretrizes para coleta e interpretação de dados sobre inovação. 3. ed. FINEP, Brasil, 2007.

PAGELL, M.; WU, Z. Building a more complete theory of sustainable supply chain management using case studies of 10 exemplars. Journal of Supply Chain Management,

v. 45, n. 2, p. 37-56, 2009.

SAVITZ, A. W.; WEBER, K. A empresa sustentável: o verdadeiro sucesso é o lucro com responsabilidade social e ambiental. Rio de Janeiro: Elsevier, 2007.

SEURING, S. Supply Chain Management for sustainable products - insights from research applying mixed methodologies. Business Strategy and the Environment, v. 20, p. 471-484, 2011.

SEURING, S.; MÜLLER, M. From a literature review to a conceptual framework for sustainable supply chain management. Journal of Cleaner Production, v. 16, p. 1699-1710, 2008.

TRIVIÑOS, A. N. S. Introdução à pesquisa em ciências sociais: a pesquisa qualitativa em educação. São Paulo: Atlas, 2007.

WU, Z.; PAGELL, M. Balancing priorities: decision-making in sustainable supply chain management. Journal of Operations Management, v. 29, p. 577-590, 2011.

YIN, R. K. Estudo de caso: planejamento e métodos. Tradução Daniel Grassi. 3. ed. Porto Alegre: Bookman, 2005. 


\section{Como citar este artigo}

ROCHA, Adilson Carlos; GOMES, Clandia Maffini; KNEIPP, Jordana - Marques. Gestão sustentável na cadeia de suprimentos e desempenho inovador $Z_{\text {em processos: }}$ um estudo na indústria do alumínio. RACE, Revista de Administração, Contabilidade e Economia, Joaçaba: Ed. Unoesc, v. 14, n. 2, p. 537-568, maio/ago. 2015. Disponível em: < http://editora.unoesc.edu.br/index. php/race >. Acesso em: dia/mês/ano.

Rocha, A. C., Gomes, C. M., \& Kneipp, J. M. (2015). Gestão sustentável na cadeia

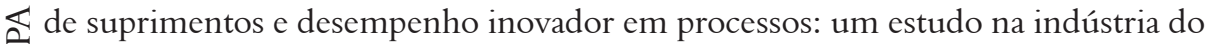
\& alumínio. RACE, Revista de Administração, Contabilidade e Economia, 14(2), 537-568. Recuperado em dia/mês/ano, de http://editora.unoesc.edu.br/index.php/race 